\title{
Meta-Analysis the Association between Obesity and Periodontitis in Adults
}

\author{
Lia Khairunnisa' ${ }^{1}$, Yulia Lanti Retno Dewi²), Eti Poncorini Pamungkasari²) \\ 1)Masters Program in Public Health, Universitas Sebelas Maret \\ 2)Department of Public Health, Faculty of Medicine, Universitas Sebelas Maret
}

\section{ABSTRACT}

Background: The risk of periodontal disease was 2.9 times higher in the obese group compared to the normal group. Periodontitis is one of the 10 most common chronic diseases affecting the world's population. Obesity contributes to an increased complexity of periodontal pathogens and an increase in inflammatory cytokines. Lifestyle changes, including a higher intake of added sugars, increase susceptibility to energy imbalances that often lead to weight gain and other long-term health consequences including periodontitis. This study aims to estimate the relationship between obesity and periodontitis in adults based on the results of a number of previous studies.

Subjects and Method: This is a systematic study and meta-analysis. The articles used in this study were obtained from several databases, including PubMed, ScienceDirect, and Google Scholar. The articles used in this study are articles that have been published from 2000-2021. The search for articles was carried out by considering the eligibility criteria defined using the PICO model. The study population was adults with an intervention in the form of obesity, comparison that was not obese and the outcomes in the form of periodontitis. This article was collected for 1 month. The keywords to search for articles were as follows: "Adult" AND "obesity" OR "body mass index" AND "periodontitis" OR "periodontal disease" AND "adjusted odds ratio". The articles included in this study are full text articles with a cross sectional study design. Articles were collected using PRISMA flow diagrams. Articles were analyzed using the Review Manager 5.3 application.

Results: A total of 11 articles were reviewed in this study. Studies have shown that obesity can increase the incidence of periodontitis in adults by 1.23 times compared to non-obese (aOR 1.23; $95 \%$ CI 1.15 to 1.33 ; $\mathrm{p}<0.001)$.

Conclusion: Obesity increases periodontitis in adults

Keywords: obesity, body mass index, periodontitis, periodontal disease

\section{Correspondence:}

Lia Khairunnisa. Masters Program in Public Health, Universitas Sebelas Maret. Jl. Ir. Sutami 36A, Surakarta 57126, Central Java. Email: liakhairunisa36@gmail.com.

\section{Cite this as:}

Khairunnisa L, Dewi YLR, Pamungkasari EP (2021). Meta-Analysis the Association between Obesity and Periodontitis in Adults. J Epidemiol Public Health. 06(02): 201-210. https://doi.org/10.26911/jepublichealth.2021.06.02.07. \section{Journal of Maternal and Child Health is licensed under a Creative Commons} Attribution-NonCommercial-ShareAlike 4.0 International License.

\section{BACKGROUND}

Obesity is a major public health problem today. Obesity is a condition of excess body fat associated with multifactorial conditions involving psychological, biochemical, metabolic, anatomic and social changes (Honne et al, 2011). The age-adjusted prevalence of obesity among US adults was 42.4\% in 2017-2018. The prevalence was 40.0\% among young adults aged 20-39 years, $44.8 \%$ among middle-aged adults aged 4059 and $42.8 \%$ among older adults aged 60 years and over (Ogden et al, 2014). Obesity and periodontitis are among the most 
common chronic disorders affecting the world's population. Obesity is a complex multifactorial chronic disease that is strongly associated with multiple comorbidities.

The relationship between obesity and periodontitis is an important topic because of their inflammatory component and their high prevalence in the adult population (Agha et al, 2017). Epidemiological studies show that obesity is also associated with periodontitis. Several authors reported that increased body mass index (BMI), waist circumference, subcutaneous body fat percentage, and serum lipid levels were associated with an increased risk of periodontitis compared with normal weight individuals (Arboleda et al, 2019).

Systemic inflammation associated with obesity may increase susceptibility to chronic infectious diseases, which may explain how obesity will affect the development of periodontal disease. Whether obesity and overweight are related to periodontitis is still debated. Many clinical studies have shown that overweight, obesity, weight gain and increased waist circumference are risk factors for the development of periodontitis or worsening periodontal status (Santos et al, 2019).

Lee's study (2014) reported that the risk of periodontal disease was at least 2.9 times higher in the obese group compared to the normal group. Han (2010) reported that BMI, waist circumference and visceral fat area had a dose-effect relationship with periodontitis. Finally, obese individuals lose more teeth and have a greater incidence of periodontal disease (Ostberg et al, 2009). Obesity has been reported to be an important risk factor for periodontal disease (Suvan et al, 2011).

In recent years, research has focused on the relationship between periodontitis and systemic disorders such as diabetes mellitus, rheumatoid arthritis, cardiovascular disease, and obesity. The relationship between obesity and periodontitis is one of the newest areas of research in periodontal medicine and the possible underlying biological mechanism remains unclear. Adipose tissue releases proinflammatory cytokines and hormones globally referred to as adipositokines, which induce inflammatory processes and impaired oxidative stress, resulting in a similar pathophysiology between the two diseases (Jagannathachary et al, 2010).

The association between obesity and periodontitis has been reported in previous studies. Obesity contributes to an increase in periodontal pathogen complexity (Maciel et al, 2016) and an increase in inflammatory cytokines (Zimmermann et al, 20-13). Lifestyle changes, including higher intakes of added sugars, increase susceptibility to energy imbalances that often lead to weight gain (Fedewa et al, 2014) and other longterm health consequences including periodontitis (Khan et al, 2018). Kim (2016) shows that there is a relationship between obesity and periodontitis, but not with dental caries.

These results indicate that obesity is a risk factor for periodontitis. Another study conducted by Pataro (2011) said that periodontitis is positively related to obesity and this relationship is more clearly seen with increasing rates of obesity. These findings demonstrate the need for early diagnosis and the inclusion of periodontal treatment in health care programs for obese women. Based on the results of previous studies obtained about dental and oral health problems in the periodontitis of obese adults, the researchers were interested in studying the relationship between obesity and periodontitis. The data obtained will be analyzed using a systematic review and meta analysis in an effort to obtain compre- 
hensive results by synthesizing the results of primary studies involving obesity and periodontal.

\section{SUBJECTS AND METHOD}

\section{Study Design}

This is a systematic study and meta-analysis. The articles used in this study were obtained from several databases, including PubMed, ScienceDirect and Google Scholar. The keywords to search for articles were as follows "Adult" AND "obesity" OR "body mass index" AND "periodontitis" OR "periodontal disease" AND "adjusted odds ratio".

\section{Inclusion Criteria}

In this study, the inclusion criteria were full text articles using an observational study design, articles in English, analysis used multivariate with adjusted odds ratio, study subjects were adults. Outcome is an examination of periodontal tissue by calculating the Community Periodontal Index (CPI).

\section{Exclusion Criteria}

Exclusion criteria in this study included articles published before 2000 and languages other than English.

4. Operational Definition of Variables In formulating the problem the researcher uses PICO. The population in this study is adults, the intervention is obesity, the comparison is not obese and the outcome is periodontitis. Obesity is a medical condition described as being overweight in the form of fat characterized by a BMI 30 . Periodontitis is an inflammatory process in the supporting tissues of the teeth caused by specific groups of micro-organisms resulting in destruction of the periodontal ligament and alveolar bone characterized by pocket formation, recession or both.

\section{Instruments}

Assessment of article quality was carried out using the Critical Appraisal Checklist for Cross-sectional Study (CEBMa, 2014).

\section{Data Analysis}

The Review Manager application (RevMan 5.3) was used in analyzing the data in this study. The results of data analysis are in the form of effect sizes and research heterogeneity. The results of the meta-analysis data processing are presented in the Forest plot and Funnel plot.

\section{RESULTS}

The process of searching for articles by searching through databases with journals can be seen in Figure 1. There were 999 articles identified from the databases, after the deletion process of published articles, 878 articles were found with 518 of them eligible for a full text review. Articles were excluded for several reasons, so that 11 articles were included in the synthesis and meta-analysis studies.

There are 11 articles from 4 continents, namely Asia, America, Australia and Europe. There are 7 studies from the Asian continent, 2 studies from the Americas, 1 study from the Australian continent and 1 study from the European continent. 
Khairunnisa et al./ Association between Obesity and Periodontitis in Adults

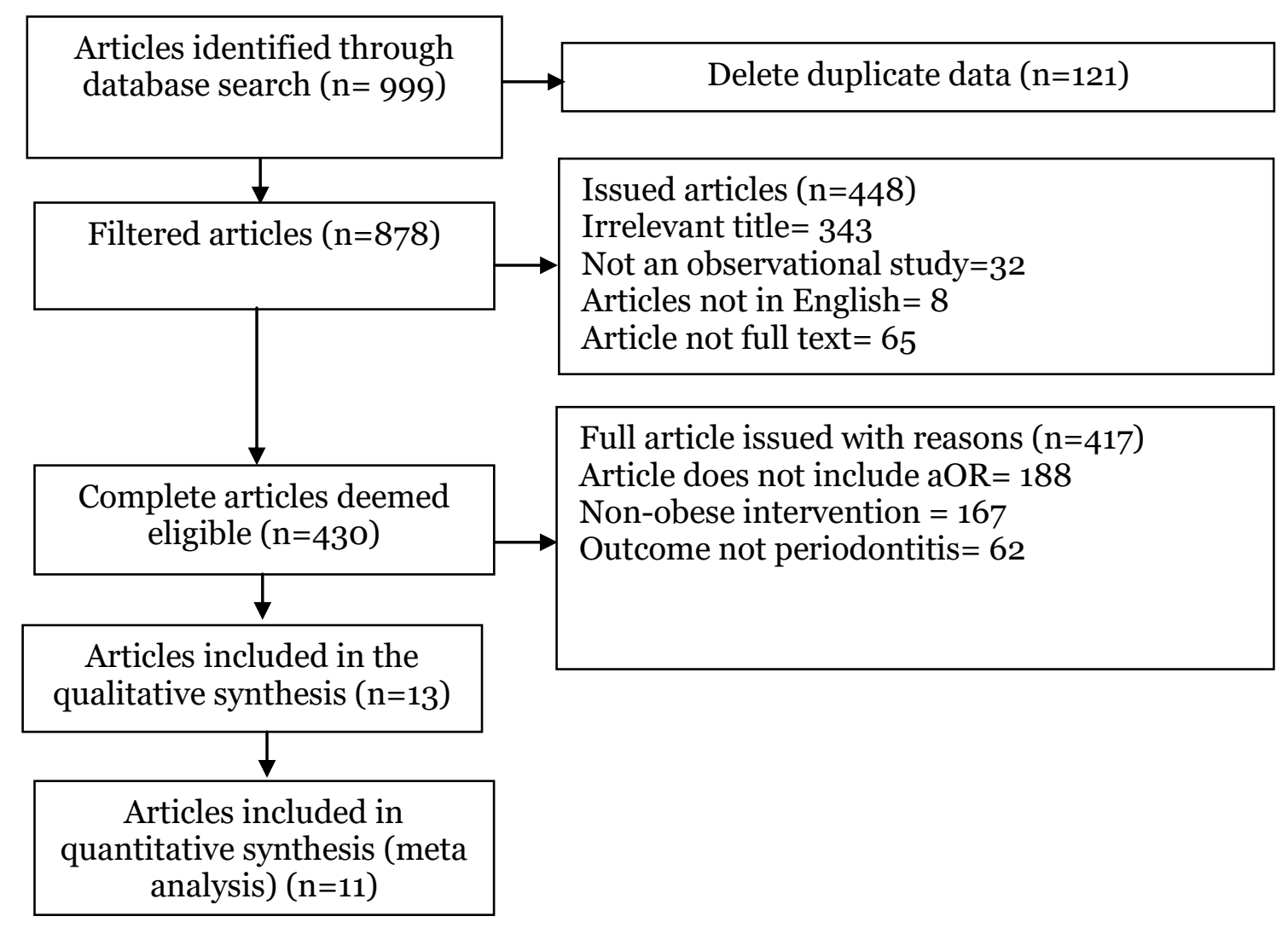

Figure 1. PRISMA flow diagram

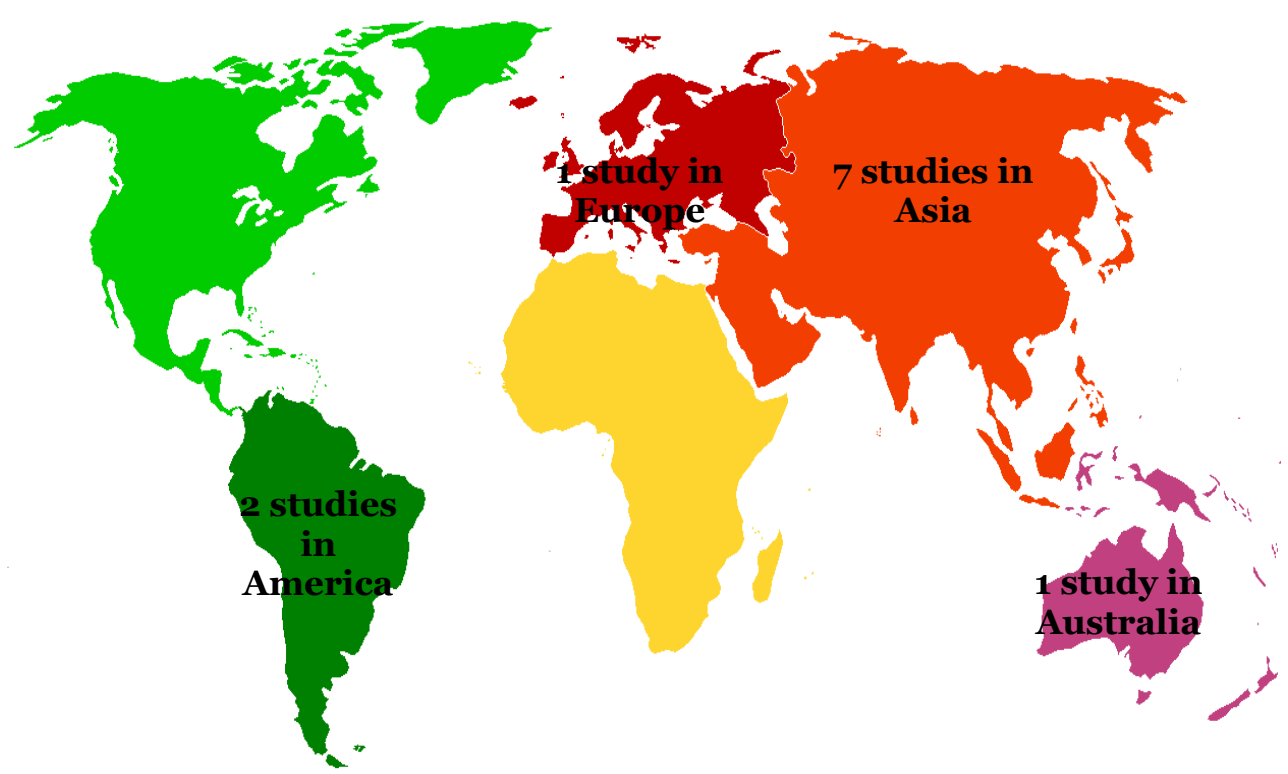

Figure 2. Map of research areas relationship between obesity and periodontitis in adults 
Table 1 Assessment of Study quality

\begin{tabular}{|c|c|c|c|c|c|c|c|c|c|c|c|c|}
\hline \multirow[b]{2}{*}{$\begin{array}{l}\mathbf{N} \\
\mathbf{o}\end{array}$} & \multirow[b]{2}{*}{ Questions of Checklist } & \multirow[b]{2}{*}{$\begin{array}{l}\text { Daallavecchia } \\
\text { et al. (2005) }\end{array}$} & \multicolumn{10}{|c|}{ Publikasi (Penulis dan Tahun) } \\
\hline & & & $\begin{array}{l}\text { Ekuni } \\
\text { et al. } \\
\text { (2008) }\end{array}$ & $\begin{array}{l}\text { Khader } \\
\text { et al. } \\
\text { (2009) }\end{array}$ & $\begin{array}{l}\text { Kim } \\
\text { et al. } \\
\text { (2011) }\end{array}$ & $\begin{array}{l}\text { Kumar } \\
\text { et al. } \\
\text { (2009) }\end{array}$ & $\begin{array}{l}\text { Gulati } \\
\text { et al. } \\
\text { (2020) }\end{array}$ & $\begin{array}{c}\text { Han et } \\
\text { al. } \\
(2010)\end{array}$ & $\begin{array}{c}\text { Kim } \\
\text { et al. } \\
(2017)\end{array}$ & $\begin{array}{l}\text { Pataro } \\
\text { et al. } \\
\text { (2011) }\end{array}$ & $\begin{array}{l}\text { Khan } \\
\text { et al. } \\
\text { (2019) }\end{array}$ & $\begin{array}{l}\text { Kongstad } \\
\text { et al. } \\
(2009)\end{array}$ \\
\hline 1 & $\begin{array}{l}\text { Do these objectives clearly address } \\
\text { the research focus/problem? } \\
\text { Are cross-sectional research }\end{array}$ & 1 & 1 & 1 & 1 & 1 & 1 & 1 & 1 & 1 & 1 & 1 \\
\hline 2 & $\begin{array}{l}\text { methods suitable to answer the } \\
\text { research question? }\end{array}$ & 1 & 1 & 1 & 1 & 1 & 1 & 1 & 1 & 1 & 1 & 1 \\
\hline 3 & $\begin{array}{l}\text { Is the research subject selection } \\
\text { method clearly written? }\end{array}$ & 1 & 1 & 1 & 1 & 1 & 1 & 1 & 1 & 1 & 1 & 1 \\
\hline 4 & $\begin{array}{l}\text { Does the sampling method not } \\
\text { introduce bias (selection)? }\end{array}$ & 1 & 1 & 1 & 1 & 1 & 1 & 1 & 1 & 1 & 1 & 1 \\
\hline 5 & $\begin{array}{l}\text { Does the research sample taken } \\
\text { represent the designated } \\
\text { population? }\end{array}$ & 1 & 1 & 1 & 1 & 1 & 1 & 1 & 1 & 1 & 1 & 1 \\
\hline 6 & $\begin{array}{l}\text { Was the sample size based on pre- } \\
\text { study considerations? }\end{array}$ & o & o & 1 & o & 1 & o & o & 1 & 1 & o & 1 \\
\hline 7 & $\begin{array}{l}\text { Was a satisfactory response } \\
\text { achieved? }\end{array}$ & o & 1 & o & o & 1 & o & 1 & 1 & 0 & 1 & o \\
\hline 8 & $\begin{array}{l}\text { Are the research instruments valid } \\
\text { and reliable? }\end{array}$ & 1 & 1 & 1 & 1 & 1 & 1 & 1 & 1 & 1 & 1 & 1 \\
\hline 9 & $\begin{array}{l}\text { Was statistical significance } \\
\text { assessed? }\end{array}$ & 1 & 1 & 1 & 1 & 1 & 1 & 1 & 1 & 1 & 1 & 1 \\
\hline 10 & $\begin{array}{l}\text { Was a confidence interval given } \\
\text { for the main outcome? }\end{array}$ & 1 & 1 & 1 & 1 & 1 & 1 & 1 & 1 & 1 & 1 & 1 \\
\hline 11 & $\begin{array}{l}\text { Have confounding factors been } \\
\text { taken into account? }\end{array}$ & 1 & 1 & 1 & 1 & 1 & 1 & 1 & 1 & 1 & 1 & 1 \\
\hline 12 & $\begin{array}{l}\text { Are the results applicable to your } \\
\text { research? }\end{array}$ & 1 & 1 & 1 & 1 & 1 & 1 & 1 & 1 & 1 & 1 & 1 \\
\hline \multicolumn{2}{|c|}{ Total } & 10 & 11 & 11 & 10 & 12 & 10 & 11 & 12 & 11 & 11 & 11 \\
\hline
\end{tabular}

Note:

Yes $=1$

$\mathrm{No}=\mathrm{O}$ 
Table 2. Description of the primary studies included in the meta-analysis

\begin{tabular}{|c|c|c|c|c|c|c|c|}
\hline Author (year) & Country & Study Design & Sample & $\begin{array}{c}\mathbf{P} \\
\text { Population }\end{array}$ & $\begin{array}{c}\text { I } \\
\text { Intervention }\end{array}$ & $\begin{array}{c}\mathrm{C} \\
\text { Comparison }\end{array}$ & $\begin{array}{c}\text { O } \\
\text { Outcome }\end{array}$ \\
\hline Daallavecchia (2005) & Brazil & Cross-sectional & 706 & Adults & Obesity & Not obese & Periodontitis \\
\hline Ekuni et al. (2008) & Japan & Cross-sectional & 618 & Adults & Obesity & Not obese & Periodontitis \\
\hline Khader et al. (2009) & Jordan & Cross-sectional & 340 & Adults & Obesity & Not obese & Periodontitis \\
\hline Kim et al. (2011) & Korea & Cross-sectional & 4.246 & Adults & Obesity & Not obese & Periodontitis \\
\hline Kumar et al. (2009) & India & Cross-sectional & 513 & Adults & Obesity & Not obese & Periodontitis \\
\hline Gulati et al.(2020) & India & Cross-sectional & 317 & Adults & Obesity & Not obese & Periodontitis \\
\hline Han (2010) & Korea & Cross-sectional & 1046 & Adults & Obesity & Not obese & Periodontitis \\
\hline Kim et al. (2017) & Korea & Cross-sectional & 11.466 & Adults & Obesity & Not obese & Periodontitis \\
\hline Pataro et al. (2011) & Brazil & Cross-sectional & 594 & Adults & Obesity & Not obese & Periodontitis \\
\hline Khan et al. (2019) & Australia & Cross-sectional & 4.170 & Adults & Obesity & Not obese & Periodontitis \\
\hline Kongstad et al. (2009) & Denmark & Cross-sectional & 1.597 & Adults & Obesity & Not obese & Periodontitis \\
\hline
\end{tabular}

*variables included in the meta-analysis study 
Khairunnisa et al./ Association between Obesity and Periodontitis in Adults

\section{a. Forest Flot}

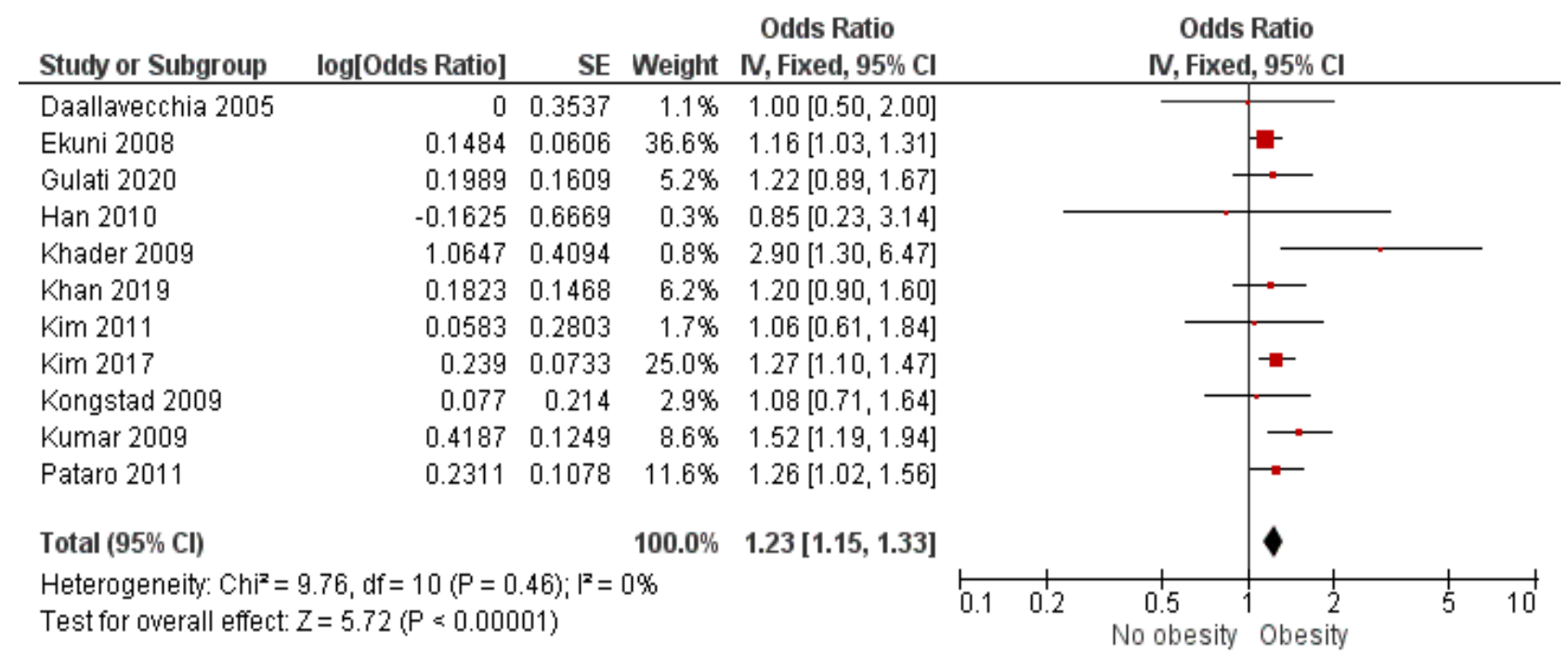

\section{Figure 3. Forest plot meta-analysis relationship between obesityand periodontitis in adults}

\section{b. Funnel Plot}

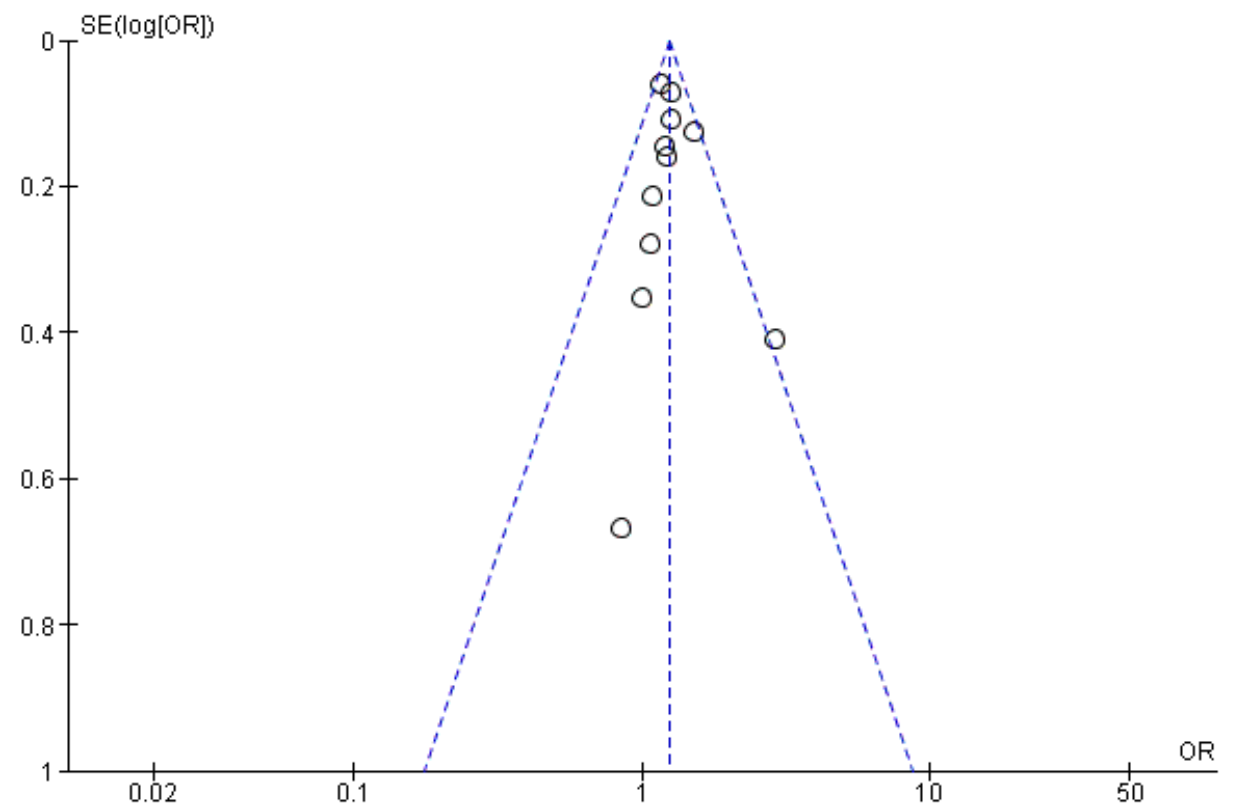

\section{Figure 4. Funnel plot meta-analysis relationship between obesity and periodontitis in adults}

The results from the forest plot (figure 3) showed that obesity could increase the incidence of periodontitis in adults by 1.23 times compared to non-obese (aOR 1.23; 95\% CI 1.15 to $1.33 ; \mathrm{p}<0.001)$. The heterogeneity of the research data shows I2 $=0 \%$ so that the distribution of the data is declared homogeneous (fixed effect model). The funnel plot (figure 4) shows no publication bias which is indicated by the 
symmetry of the right and left plots, as evidenced by the 4 plots on the left, 2 plots on the right and 5 plots touching the vertical line. The plot on the left has a standard error between 0.2 and 0.8 , the plot on the right has a standard error between 0 and 0.6 and the plot that touches the vertical line has a standard error between 0 and 0.2 .

\section{DISCUSSION}

This study is a systematic review and metaanalysis that raises the theme of the relationship between obesity and periodontitis in adults. This systematic review and metaanalysis research uses research that controls confounding factors which can be seen from the inclusion requirements of the study, namely using multivariate analysis and the statistical results reported are adjusted odd ratio (aOR).

The combined results of the relationship between obesity and periodontitis in adults were processed using the RevMan 5.3 application, while the results of a systematic review and meta-analysis of this study were presented in the form of forest plots and funnel plots.

The results of the meta-analysis of cross-sectional studies showed that obesity can increase the incidence of periodontitis in adults as much as 1.23 times compared to non-obese (aOR 1.23; 95\% CI 1.15 to 1.33; $\mathrm{p}<0.001)$. This is in accordance with Santos (2019), which showed that periodontitis was associated with obesity, but not with being overweight. A strong association was found between obesity and periodontitis in this study. The risk of severe periodontitis is 3 times higher in obese individuals.

This study is strengthened by the research of Kim et al (2017), that this study shows a relationship between BMI and oral health status in Korean adults. The risk of periodontitis increases with BMI. However, dental caries did not differ significantly. These results suggest that obesity is a risk factor for periodontitis, oral health professionals should be aware of this risk. Obesity alters the physiologic environment associated with periodontal disease, such as the periodontal microflora, and increases susceptibility to various infections.

Another study by Haffajee and Socransky (2009) observed overgrowth of Tannerella forsythia in subgingival biofilms in periodontally healthy obese individuals, which may put them at risk for periodontitis. This suggests a possible association between obesity and periodontitis.

Moura-Grec et al. (2014) mentioned that the results of this systematic review provide evidence that there is an association between overweight/obesity and periodontal infection, but the strength of the association may be underestimated due to the heterogeneity of the study. Thus, all health workers including the dental team can provide education, prevention and treatment for obese patients about the risk of periodontal disease.

\section{AUTHOR CONTRIBUTION}

Lia is the main researcher who selects the topic, searches and collects research data. Yulia Lanti Retno Dewi and Eti Poncorini Pamungkasari played a role in analyzing data and reviewing research documents.

\section{FUNDING AND SPONSORSHIP}

This study is self-funded.

\section{CONFLICT OF INTEREST}

There is no conflict of interest in this study.

ACKNOWLEDGEMENT

We are very grateful to the database providers, PubMed, Science Direct and Google Scholar. 


\section{REFERENCES}

Agha M, Agha R (2017). The rising prevalence of obesity: part B - Public health policy solutions. J Surg Oncol. 2 (7): 1-4. https://doi.org/ 10.1097/IJ9.ooooooooooooo019.

Arboleda S, Vargas M, Losada S, Pinto A (2019). Review of obesity and periodontitis: an epidemiological view. Br. Dent. J. 227(3): 235-239. https://doi.org/10.1038/s41415-019-0611-1

Fedewa MV, Das BM, Evans EM, Dishman RK (2014). Change in weight and adiposity in college students. Am J Prev Med. 47(5): 641-652. https://doi.org/10.1016/j.amepre.2014.07.035.

Haffajee AD, Socransky SS. Relation of body mass index, periodontitis and Tannerella forsythia. J Clin Periodontol. 2009 Feb;36(2):89-99. https://doi.org/10.1111/j.1600-051X.2008.01356.x.

Honne T, Pentapati K, Kumar N, Acharya S (2011). Relationship between obesity /overweight status, sugar consumption and dental caries among adolescents in South India.Int J Dent Hyg. 10 (4) : 240-244. https://doi.org/ 10.1111/j.1601-5037.2011. 00534.x.

Jagannathachary S, Kamaraj D (2010). Obesity and periodontal disease . J Indian Soc Periodontol 14(2): 96-100. https://doi.org/10.4103/0972-124X.70827 .

Kim HD, Shin MS, Kim HT, Kim MS, Ahn YB (2016). Incipient periodontitis and salivary molecules among Korean adults: association and screening ability. J Clin Periodontol. 43(12): 10321040. https://doi.org/10.1111/jcpe.12607.

Kim YS, Kim JH (2017). Body mass index and oral health status in Korean adults: the Fifth Korea National Health and Nutrition Examination
Survey. Int J Dent Hyg. 15(3): 172178. https://doi.org/ 10.1111/idh.12207.

Lee KS, Kim EK, Kim JW, Choi YH, Mechant AT, Song KB, Lee HK (2014). The relationship between metabolic conditions and prevalence of periodontal disease in rural Korean elderly. Arch Gerontol Geriatr. 58(1) : 125-129. https://doi.org/10.1016/ j.archger.2013.08.011.

Moura-Grec PGD, Marsicano JA, Carvalho CAPD, Sales-Peres SHDC (2014). Obesity and periodontitis: systematic review and meta-analysis. CienSaude Colet. 19(6): 17631772. https://doi.org/10.1590/1413-81232014196.13482013.

Ostberg AL, Nyholm M, Gullberg B, Råstam L, Lindblad U (2009). Tooth loss and obesity in a defined Swedish population. Scand J Public Health. 37(4): 427-433. https://doi.org/10.1177/1403494808099964.

Pataro AL, Costa FO, Cortelli SC, Cortelli JR, Abreu MHNG, Costa JE (2011). Association between severity of body mass index and periodontal condition in women.Clin.Oral Investig. 16(3): 727-734. https://doi.org/10.1007/so0784-011-0554-7.

Santos T, Curyb PR, Santosc E, Vasconcelosa R, Jean N, Ramalhod LMP (2019). Association Between Severe Periodontitis and Obesity Degree: A Preliminary Study. oral hlthprev dent. 17(2): 173-176. https://doi.org/ 10.3290/j.ohpd.a42374.

Suvan J, D'Aiuto F, Moles DR, Petrie A, Donos N (2011). Association between overweight/obesity and periodontitis in adults A systematic review.Int $\mathrm{J}$ Obes (Lond). 12(5): e381-e404. https://doi.org/10.1111/j.1467789x.2010.00808. 
Khairunnisa et al./ Association between Obesity and Periodontitis in Adults

Zimmermann GS, Bastos MF, Dias Goncalves TE, Chambrone L, Duarte PM (2013). Local and circulating levels of adipocytokines in obese and normal weight individuals with chronic periodontitis. J. Periodontol. 84(5): $624-$ 633. https://doi.org/10.1902/jop.2012.120254 . 